\title{
The Status and Future of Action Research: An Interview with Professor David Coghlan

\author{
David Coghlan and Erik Lindhult
}

\author{
" The innovation process is about how people think, how they") \\ create new perspectives and technologies to address pertinent \\ issues, more than it is about the externalized data and \\ technologies apart from the human mind... So, published \\ accounts of how people work through the cognitive and \\ collaborative challenges of an innovation initiative is what I \\ value rather than the impersonal reports of studies based on \\ quantitative analysis.
}

\author{
David Coghlan \\ Professor Emeritus and Author
}

\section{Introduction by Erik Lindhult}

The recently published special issues on action research in the TIM Review (April 2019: timreview.ca/issue/2019/april and May 2019: timreview.ca/issue/2019/may) are an indicator of the viability and fruitfulness of expanding this type of approach for research and practical development in the technology and innovation management area.

To further clarify the contemporary status as well as opportunities and challenges for future development, we invited David Coghlan, Professor Emeritus at the Trinity Business School, University of Dublin Trinity College, a leading scholar on action research and a founding father of modern approaches in the area, such as "insider action research", to give his personal reflection and views. The interview also touches on patterns and themes in the two special issues and how they point to contemporary status, opportunities, and challenges of action research.

The interview starts with David Coghlan's view on action research as experience-based and value-oriented inquiry by people into issues that concerns them with an ambition to involve everyone in improving the systems in which they participate. Dimensions and issues in insider action research are also explored, such as the relationships between insider and outsider positions and perspectives. Then, we discuss the landscape of action research today, where David is on the one hand enthused about the proliferation of exciting action research work but at the same time sees budding scholars forced do comply with philosophies of research and evaluation criteria of universities and journals that sometimes have a restrictive view on knowledge related to experience and action. The interview explores some dimensions of a required intellectual conversion in research and academia: philosophically, in education, what does it mean for scholars in the technology innovation management (TIM) area and how does this relate to patterns seen the recent two special issues in the TIM Review. David points out that innovation processes enable people to create something new in addressing pertinent issues. In our volatile, unpredictable, complex, and ambiguous (VUCA) world, it is essential to attend, in the present tense, to dynamic operations and make accounts of how people work through the cognitive and collaborative challenges of innovation initiatives.

The last section of the conversation looks into opportunities and recommendations for further development and their implications for the epistemic ecosystem of actors, for example, issues of quality, publication of action research work, and innovative action by researchers, academic environments, founders of research, journal editors, etc., that can make the system more conducive to action research. 


\title{
The Status and Future of Action Research: An Interview with Professor David Coghlan
}

\author{
David Coghlan and Erik Lindhult
}

\section{Interview with David Coghlan}

Lindhult: David, what is the background for your engagement in the action research field? What made you interested in action research and participatory methods?

Coghlan: When I was introduced to the field of organization development in the early 1970s, through the writings of the organization development pioneers such as Edgar Schein and Richard Beckhard, I discovered a collaborative organizational and systems approach that parallels the individual therapeutic work of Carl Rogers with which I was familiar. Rogers in his field and Schein and Beckhard in theirs were articulating a philosophy, methodology, and methods on how to work with people in a facilitative manner that supported those affected by a change to make the change themselves. Then, in the 1980s, I was introduced to Lewin, his notion of action research, and the rich tradition that flowed from his work. In the subsequent decades, from my participation in the action research community in US, UK, and in Europe, I grew in my understanding, appreciation, and internalization of action research's theory and practice and, in particular, in the core insight that we do collaborative research on things that matter.

\section{Lindhult: What are you working on right now?}

Coghlan: Since I have become a professor emeritus and have moved into a quieter phase of reflective living, I am focusing on interiority and on my educational role, which I express through reflective writing about philosophical and methodological issues (Coghlan, 2017). I continue to develop my work on insider action research (The 5th edition of Doing Action Research in Your Own Organization was published recently; Coghlan, 2019) and through giving seminars on action research's philosophies and methodologies.

Lindhult: What are the special considerations and features in conducting this type of research?

Coghlan: On doing action research as an insider, I think that enabling people to engage in the present tense by attending to their experience, inquiring into it with other insiders, formulating and testing answers in a context of a value-oriented inquiry, intentionality and action is significant for people to pursue in addressing issues that concern them and to generate actionable knowledge through the process. Seeing the potential of action research is foundational. Doing it follows. Everyone improving the systems in which they participate is a powerful alternative to leaving it to experts.
Lindhult: We can agree that people create knowledge and change through action in their own organizations, but some knowledge is tacit and may be of varying quality, so how do we as action researchers best go about capturing the richness and ensuring the quality of knowledge created in change processes?

Coghlan: By engaging with others in collaborative ventures and consistently attempting to inquire into our experience - how we are understanding it and questioning the experience and understanding of others - we can draw out what is tacit. So, rather than discussing issues and debating positions, if we explore how we have come to know, then we have the ground for fruitful dialogue. Argyris' action science provides tools for uncovering privately-held inferences and for testing assumptions, and Schein's humble inquiry gives us a way of working with others.

Lindhult: You emphasize "actionable knowledge", which can be interpreted as knowledge in action research having the primary goal of supporting action, should there not also be processes geared for "knowledgeable action"?

Coghlan: "Actionable knowledge" is typically defined as knowledge that is useful for practitioners and robust for scholars. Practical knowing subsumes other forms of knowing as we draw on both theory and reflected practice so as to become skilled. So, if by "knowledgeable action" you mean that our action is informed by knowledge, then I affirm that. I see the role of understanding the context plays as essential.

Lindhult: You have been leading the methodological development of insider action research. Why have you found this development particularly important? What are the differences in the considerations and features of insider action research compared to outsider action research?

Coghlan: In the late 1990s, I was working in an executive action research master's program where the executives were doing their dissertations on an initiative they were taking in their organizations. I found that most action research literature talked about the action researcher as an external agent (for example, Greenwood and Levin refer to the "friendly outsider"). But the executives with whom I was working were doing action research through their managerial roles in their own organizations. So, from the discussions with them, I began to put class notes together, and these eventually became the book Doing Action Research in Your Own 


\section{The Status and Future of Action Research: An Interview with Professor David Coghlan} David Coghlan and Erik Lindhult

Organization which is now in its fifth edition (Coghlan, 2019). From my work with these executives over several cohorts, some core themes emerged: preunderstanding (managing being familiar with the organization and thereby blind to the culture), role duality (managing holding both a management role and a researcher role, with ambiguities, tensions or conflicts that might arise between them) and managing organizational politics (as the manager may wish to stay in the organization when the research is completed). Since 2001, these themes have been confirmed as key to insider action research. As so many executive programs, across business, healthcare, nursing, social work, etc. have an action project or thesis that the participants have to do, this work of mine has met a theoretical, methodological, and practical need.

Lindhult: How is an insider perspective related to outsider perspectives in research? For example, Levin saw research perspectives as always having an aspect of outsider perspective. What are the advantages of insider perspectives? What about knowledge interests? Does it also imply a risk that insider (research) perspectives can be "co-opted" so that some of the status as a research perspective is lost?

Coghlan: The notion of "insider" and "outsider" is a social construction and is not a pure distinction a lot of the time. One can be an insider to the organization as a whole and be perceived as an outsider by the particular department where the action research is taking place. So, the clarification of role as perceived and role as enacted is a task to be explored in any insider action research project. Insiders have a rich knowledge, though a lot of it may be tacit and not brought to explicit awareness. Hence, my emphasis on preunderstanding as a key challenge for insiders, that is, to build on the closeness they have to the setting and to achieve a critical questioning of what it is they don't know or are blind to. Hence, the value of having a research group (as separate from the project management group) that challenges thinking and tries to uncover privately held assumptions and interpretations. There may be non-organizational members in this group who perform an important role in asking critical questions.

But your question also points to a different dynamic. When we think of the subject as subject, then we can talk about our self-awareness, not from outside ourselves but as integral to consciousness. We don't become outsiders to ourselves when we engage in critical thinking. When we are watching a thriller on TV, we can be aware of ourselves becoming tense at particular exciting moments. So, we can attend to data of consciousness (what we are thinking, feeling, etc.) and to data of sense (what we are seeing, hearing, etc.) at the same time. This is what I call "interiority" and is what I understand as being a philosophical approach to dealing with the philosophical issues within research philosophies (Coghlan et al., 2019). I have argued that interiority forms the "new enlightenment", a synthesis of modern thesis and postmodern antithesis (Coghlan, 2017).

\section{The Landscape of Action Research Today}

Lindhult: How would you describe the status and landscape of action research today? What trends in its development do you see?

Coghlan: I am somewhat conflicted when I look at the action research landscape. On the one hand, I am enthused as I think that there is exciting action research work being done on our key global and social challenges: sustainability, working with migrants, inequality, innovation, and so on. On the other hand, I feel depressed as I see budding scholars being forced to comply with requirements to publish in journals that are locked into a philosophy of research that excludes action for their careers. It is the restrictive view of what knowledge is worth producing and how scholars are evaluated that bothers me. While this is not a new challenge, in some respects it has worsened because the criteria for how universities judge scholarship and how they themselves are judged are narrowing. There are powerful structural forces inhibiting the development of action research. I think that there is a need for an intellectual conversion to understand how there are many approaches to research, and the academy need not confine itself to one approach. So, investing in creating an eclectic environment for a range of rigorous, relevant, and reflective research should be encouraged.

Lindhult: How would your proposals for criteria for how universities judge scholarship differ from the dominant ones? Do you see them emerging in some university settings?

Coghlan: Davydd Greenwood and Morten Levin have written extensively on this topic and make the case for a complete redefining of the university. In the context of this interview, I'm simply arguing for a more eclectic notion of research that accommodates different forms and methodologies of knowledge production and that values how different forms of knowledge contribute to the sustainability and development of our planet. 


\section{The Status and Future of Action Research: An Interview with Professor David Coghlan} David Coghlan and Erik Lindhult

Lindhult: Do you see that this type of research is present in the TIM area? What are positive potentials and barriers for its further development?

Coghlan: Research is undertaken by people and so, in my view, how people work from experience, through questioning to understanding to verification and judgment and to action, is what is most valuable. The innovation process is about how people think, how they create new perspectives and technologies to address pertinent issues, more than it is about the externalized data and technologies apart from the human mind. In this volatile, unpredictable, complex, and ambiguous (VUCA) world, attending in the present tense to the dynamic operations of how we come to know and to collaborate are essential. So, published accounts of how people work through the cognitive and collaborative challenges of an innovation initiative is what I value rather than the impersonal reports of studies based on quantitative analysis. How we deal with VUCA challenges as they emerge is not amenable to research approaches that depend on fixed variables.

Lindhult: What do you recognize as significant in the two special issues in the TIM Review from your horizon? How does it relate to the contemporary status, opportunities, and challenges of action research?

Coghlan: The two special issues of the TIM Review (April 2019: timreview.ca/issue/2019/april and May 2019: timreview.ca/issue/2019/may) demonstrate how action research can be undertaken in a variety of contexts, where there are real issues to be addressed and useful knowledge to be generated by addressing the issues and reflecting on the challenges in addressing them. I point to accounts of crossing boundaries (organizational and disciplinary), the collaborative challenges, including with different stakeholders, dealing with emergent issues as providing reflective accounts of researching-in-action.

But action research is not consulting or project management, though many of its process are shared. The word "research" is important as it denotes an intention to contribute knowledge to a setting beyond the immediacy of any given initiative. This is a central difference. In terms of the quality dimensions we've discussed, action research must be explicit in showing an understanding of the context (both the practical strategic and operational context of the issue and the literature on research in this area), the dynamics of collaborative engagement across boundaries, disciplines, and the engagement in shared action and reflection, so that the dual outcomes of practical and actionable knowledge are evident in how they emerged from the collaborative engagement and how they contribute to the context. The two special issues of the TIM Review also provide several theoretical articles about the nature of action research, which are very informative and demonstrate the theoretical foundations of action research.

Lindhult: You are also pointing to the philosophy of science as crucial. What kind of philosophy for research would be more supportive of this kind of research, and how would it change how universities judge scholarship? Are there some good examples?

Coghlan: There are many colleagues who believe that, if there are no numbers in a work, then it is not real research. For them even case studies are suspect. And, even more so, if there is action and subjectivity, then the breach of the canons of statistical objectivity and universal theory in action research is too much. This is how researchers are trained and socialized, and it is the dominant model. In recent publications, I have begun arguing for "interiority", that is, attending to data of consciousness as well as data of sense so that how we know is as important as what we know. The two special issues of the TIM Review provide solid examples of this kind of research in action.

\section{Future Opportunities and Recommendations for Further Development}

Lindhult: What opportunities do you see for further developments in the action research domain?

Coghlan: The need for an intellectual conversion to understand how there are many approaches to research and the academy need not confine itself to one approach. So, investment in creating an eclectic environment for a range of rigorous, relevant, and reflective research needs to be encouraged.

Lindhult: You have done a lot of work in the areas of education, skills, and textbook development. How can competence development be organized, be it research methods courses or in other forms of learning processes, so as to best further the kind of inquiry skills you see as fundamental in action research?

Coghlan: How often is it that so-called "research methods" courses typically point to the design and implementation of surveys and the writing of cases while rarely even touching on the development of introspective interiority and face-to-face collaborative inquiry 


\title{
The Status and Future of Action Research: An Interview with Professor David Coghlan
}

\author{
David Coghlan and Erik Lindhult
}

skills? Of course, researchers need to learn how to work with numbers, and there are fundamentals that need to be taught. But, in parallel, I think it is valuable to engage students and aspirant researchers in practicums and internships where they engage in action and then come together to reflect on their experience by questioning what took place (or didn't), questioning their questioning and exploring how they might understand (supported by relevant reading) and so on. Through this method, they learn to process their own thinking and learn to engage in a collaborative inquiry of others' thinking.

Lindhult: For researchers and other actors considering initiating an action research initiative instead of a "normal" research project, what is, in your view, most important to think about?

Coghlan: Rather than starting with a theory and a review of literature, start with the existing practical situation with which there is a concern or potential for development and work from there in building a coalition to address it and in doing so draw on the trove of others' work, both practical and theoretical, to build understanding of what's involved. The guiding questions are: What do we want to do to address our concern? Who needs to be involved? How can what we do and what we learn be of use to others, both practitioners and scholars?

If we start with our worldview (what research philosophy calls "ontology") of what we believe about the world and people - I heard Bjørn Gustavsen say that his worldview was democracy theory and so any research he was doing would have to be participative because that's what democracy is about - then methodology and choice of methods flow from that. We can then ask how we design what we want to do and capture the process in a manner that is rigorous and transparent for others to learn from it.

Lindhult: What is your own worldview? Does it also relate to democracy? What does it mean for methodology and research design?

Coghlan: The human person is a symbolic animal, and the core of human living in large measure is mediated through acts of meaning. We express ourselves through language, art, symbols, rituals, how we live, and what we do. Meaning is not only what is experienced but is also what is questioned, understood, interpreted, and affirmed. Organization and community are only possible through a common ground of meaning, which find expression in the articulation of shared values and aims and in shared actions. Action research works through interpreting events and intentional acts that envisage ends, select means, and work collaboratively to achieve those ends. It works by understanding how these ends are achieved, by critiquing these ends, and by deciding whether we want to achieve these ends or something different. Beyond the world we know about, there is the future we create by intending, investigating possibilities, planning, weighing options, taking action, and learning. We are constantly engaging in acts of meaning in our experiencing, our understanding, our judgments, our decisions, and our actions. So. for me, exploring the meaning of what we care about, what concerns us, and what we might want to do about it is both an individual process of valuing and a collaborative process of coming to a shared understanding and common courses of action. In this way, it is democratic as we have so many examples in history of groups coercing others to adopt their meaning and trying to destroy dialogue.

Lindhult: What about publication, the dominant measure of academic success? Action research is often perceived to be more difficult to publish, particularly in higher-ranked journals. In a publish-or-perish academic climate, this is a challenge for people considering doing action research in the academic community. However, in a literature review in the special issue, you are mentioned as one of the most productive scholars in the action research field (Guertler et al., 2019). Thus, you have been successful in combining a focus on action research and publication productivity. Another study in the special issues on publication outlets for action research did not find lower frequency of action research publication in high ranked journals (Hoppe, 2019), thus partly questioning received assumptions. How should action research scholars think concerning publication? Please share your thoughts and experience on how scholars can develop viable publication strategies and tactics?

Coghlan: Journals and their editors reflect the culture in which they have been trained and formed. And, as I said earlier, this is becoming narrower. As the number of journals has proliferated, they have narrowed further. I submitted an action research paper to a conference some years ago and the reviewer's opening line was "I have no problem with a sample of one". That told me that this reviewer had no idea of what I was doing in my action research paper if they had to assert their starting point in terms of sample size. Due to my age, I am now immune from the publish-or-perish 


\title{
The Status and Future of Action Research: An Interview with Professor David Coghlan
}

\author{
David Coghlan and Erik Lindhult
}

pressure and so I pursue journals that I think will be interested in what I have to say. But it is a struggle and I get both outright rejections and encouraging challenges to develop my thought. This is not much use to the young scholar who needs publications in high-ranked journals for tenure and promotion. Students of Edgar Schein report that he would say "just get your work out there". With electronic access and the use of key words, anyone's work is accessible. At the same time, reporting on an action research work in an article, writers need to follow some key norms that editors and reviewers can recognize. They need to show how action research is a normal mode of inquiry that arises in a practical and an academic context and how the engagement in addressing the issue is transparent in how participants were engaged, questions were asked, answers were subjected to rigorous questioning, and how there is a consistency between the outcomes, the engagement in action and inquiry, the relationship between the participants in that action and inquiry, and where it fits with what questions were posed from the practical and academic contexts. It is interesting how some journals are now insisting that authors have a section on implications for practice as well as for further research.

Lindhult: What are your recommendations for the ecosystem of actors - academics; professionals in industry, public service, and civil society; policy makers; sponsors and funders; journal editors; etc?

Coghlan: Let's realize the potential of an extended epistemology - different ways of knowing - and give value to a philosophy of practical knowing, and not only to its propositional form. While the term "science" is problematic once we move beyond the natural sciences, if we hold a broader understanding of different forms of inquiry and how they can be conducted in a manner that meets defined quality criteria, then we can produce actionable knowledge, that is knowledge that works for practitioners and is robust for scholars.

Lindhult: The discourse and views on quality in research and science are varied and in flux. The special issues contain efforts to clarify the meaning of scientific excellence and research quality in action and participatory research. You have also been contributing to this debate. How can we clarify research quality, in your view?

Coghlan: It is only in the past fifteen or so years that the action research community has articulated what might be the quality dimensions of action research. How would we recognize good action research? You have written an extensive exploration of this subject in the
May issue of the TIM Review. Rami Shani and I have framed four factors: i) how the context is shown to be understood; ii) the quality of the relationships between members and between members and researchers in working and inquiring together; iii) the quality of the action research process in the intertwining dual focus on both the action and the inquiry processes; and iv) the dual outcomes of action research in creating some level of sustainability (human, social, economic, ecological) and the co-generation of actionable knowledge (Coghlan \& Shani, 2014; Shani \& Coghlan, 2019). These four factors comprise a comprehensive framework as they capture the core of action research and the complex cause-and-effect dynamics within each factor and between factors. They provide a unifying lens into wide variety of the reported studies in the literature, whether or not the factors are discussed explicitly in a high-level guide for the action researcher. It allows the distinct nature of each action research effort to emerge, and it magnifies the added value of each study.

Lindhult: What advice would you give to different ecosystem actors to help to realize the potential of action research?

Coghlan: Maybe it's about being innovative and taking risks. The system won't change unless we change it.

Lindhult: I agree. There is a need for innovative ideas and taking some risks in pursuing them by all actors involved. Academics and academic environments need be open to different ways of understanding and pursuing scientific inquiry and also for developing appropriate competencies for doing action research. Professionals need to be open to Socratic knowledge of the limits of their knowledge through critical questioning, and taking time for reflective and interactive learning through collaborative knowledge creation. Policy makers need to consider the goals and steering parameters for science and its contribution to society, and the appropriate incentives for researchers (e.g., publications, focusing on important societal challenges and concerns of stakeholders). Sponsors and funders need to be open to engaged research that deals collaboratively with important concerns without promising general models or easy solutions. Journal editors need to be open to research building sound knowledge from experience and accounts of how people work through the cognitive and collaborative challenges of innovation initiatives. These actions combined can build a movement towards an epistemological ecosystem conducive for action research.

Coghlan: Well put. I agree. 


\section{The Status and Future of Action Research: An Interview with Professor David Coghlan}

\section{David Coghlan and Erik Lindhult}

Lindhult: What are your thoughts on improving this ecosystem in constructing a good future for action research?

Coghlan: As I've said, let's go after things that matter and do research on how we build collaboration to address them and build rigorous, relevant, and reflective methods to cogenerate actionable knowledge. In the VUCA world, this involves direct engagement in addressing what some authors refer to as "wicked problems", which require innovation. If we keep publishing rich accounts, then our work is getting out there and can be accessed readily.

Lindhult: In this emerging VUCA world, do you see some areas of interest that provide opportunities for action research scholars and practitioners?

Coghlan: No. The whole point is that our experience constantly throws up new challenges. That's what VUCA means. If I were to focus on my areas of interest, then I would be closing myself to the volatile, unpredictable, complex, and ambiguous dynamic of our world. This takes me back to the emphasis I've been placing on context. Action research arises from a real issue in a real context, not the interests of researchers. So, the opportunities for action research are the issues we care about. If we lose sight of that, then we have lost the vision of action research.

Lindhult: Thank you so much, David, for your interesting and valuable responses.

Coghlan: You're welcome.
David Coghlan is Professor Emeritus at the Trinity Business School, Trinity College, Dublin, Ireland, and is a Fellow Emeritus of the College. He specializes in organization development and action research and participates actively in the both communities internationally. He has published over 180 articles and book chapters. Recent books include: Doing Action Research in Your Own Organization (5th ed. Sage: London, 2019); Conducting Action Research for Business and Management Students (with Rami Shani, Sage: London, 2018), Inside Organizations (Sage: London, 2016). He is co-editor (with Mary Brydon-Miller) of the SAGE Encyclopedia of Action Research and (with Rami Shani) of the four-volume sets, Fundamentals of Organization Development (Sage: London, 2010) and Action Research in Business and Management (Sage: London, 2016). He is a member of the editorial advisory board of several journals, including Action Research, The Journal of Applied Behavioral Science, Action Learning: Research and Practice, Systemic Practice and Action Research, and OD Review.

Erik Lindhult $(\mathrm{PhD})$ is a Senior Lecturer in Innovation Management and Entrepreneurship at Mälardalen University in Sweden. He received his doctoral degree in Industrial Management from the Royal Institute of Technology in Stockholm, in the area of Scandinavian dialogue democratic approach to innovation and action research. His main area of research is participatory, collaborative, and democratic innovation and change management, as well as entrepreneurship for a sustainable development of society. His research interests also involve collaborative research methodologies, including action research and interactive research. He has been involved in a wide range of collaborative $R \& D$ projects in the private, public, and cooperative sectors, in areas such as organizational development, incubator and science park development, service innovation, societal entrepreneurship, sustainable innovation, and school development. He is a board member of the Swedish Participatory Action Research Society (SPARC) and the Swedish Interactive Research Association (SIRA), as well as an expert advisor to the EU SWAFS Horizon 2020 research committee. 


\section{The Status and Future of Action Research: An Interview with Professor David Coghlan}

David Coghlan and Erik Lindhult

\section{References}

Coghlan, D. 2017. How Might We Learn about the Philosophy of ODC Research from 24 Volumes of ROCD? An Invitation to Interiority. In A. B. (Rami) Shani \& D. A. Noumair (Eds.), Research in Organizational Change and Development, Volume 25: 335-361. Bingley, UK: Emerald.

http://doi.org/10.1108/S0897-301620170000025010

Coghlan, D. 2019. Doing Action Research in Your Own Organization (5th ed.). London: SAGE.

Coghlan, D., \& Shani, A. B. 2014. Creating Action Research Quality in Organization Development: Rigorous, Reflective and Relevant. Systemic Practice and Action Research, 27(6): 523-536. https://doi.org/10.1007/s11213-013-9311-y

Coghlan, D., Shani, A. B., \& Hay. G. W. 2019. Toward a Social Science Philosophy of Organization Development and Change. In D. A. Noumair \& A. B. (Rami) Shani (Eds)., Research in Organizational Change and Development, Volume 27: 1-29. Bingley, UK: Emerald.

Guertler, M., Sick, N., \& Kriz, A. 2019. A Discipline-Spanning Overview of Action Research and Its Implications for Technology and Innovation Management. Technology Innovation Management Review, 9(4): 48-65.

http://doi.org/10.22215/timreview/1233

Hoppe, M. 2019. Choosing an Outlet for Action Research: Publication Patterns in Innovation Journals. Technology Innovation Management Review, 9(4): 66-77.

http://doi.org/10.22215/timreview/1234

Shani, A. B., \& Coghlan, D. 2019. Action Research in Business and Management: A Reflective Review. Action Research, Online First. http://doi.org/10.1177/1476750319852147

Citation: Coghlan, D., \& Lindhult, E. 2019. The Status and Future of Action Research: An Interview with

Professor David Coghlan. Technology Innovation

Management Review, 9(6): 42-49.

http://doi.org/10.22215/timreview/1248

Keywords: action research, insider action research, interview, David Coghlan, interiority, reflection 


\section{Academic Affiliations and Funding Acknowledgements}
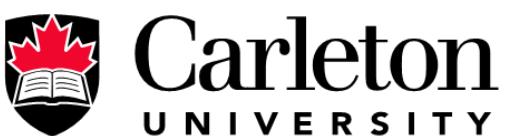

U N I V E R S I T Y

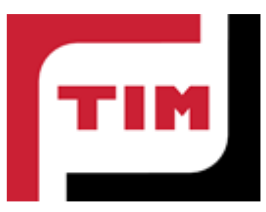

Technology Innovation Management (TIM; timprogram.ca) is an international master's level program at Carleton University in Ottawa, Canada. It leads to a Master of Applied Science (M.A.Sc.) degree, a Master of Engineering (M.Eng.) degree, or a Master of Entrepreneurship (M.Ent.) degree. The objective of this program is to train aspiring entrepreneurs on creating wealth at the early stages of company or opportunity lifecycles.

- The TIM Review is published in association with and receives partial funding from the TIM program. 